Article

\title{
Mini-Map for Gamers Who Walk and Teleport in a Virtual Stronghold
}

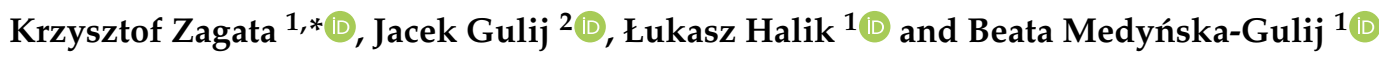 \\ 1 Department of Cartography and Geomatics, Faculty of Geographical and Geological Sciences, \\ Adam Mickiewicz University, 61-712 Poznań, Poland; lhalik@amu.edu.pl (Ł.H.); bmg@amu.edu.pl (B.M.-G.) \\ 2 Faculty of Computing and Telecommunications, Poznan University of Technology, 60-965 Poznań, Poland; \\ jacek.gulij@student.put.poznan.pl \\ * Correspondence: krzysztof.zagata@amu.edu.pl
}

Citation: Zagata, K.; Gulij, J.; Halik, Ł.; Medyńska-Gulij, B. Mini-Map for Gamers Who Walk and Teleport in a Virtual Stronghold. ISPRS Int. J. Geo-Inf. 2021, 10, 96. https:// doi.org/10.3390/ijgi10020096

Academic Editors: Wolfgang Kainz and Georg Gartner

Received: 29 December 2020

Accepted: 19 February 2021

Published: 22 February 2021

Publisher's Note: MDPI stays neutral with regard to jurisdictional claims in published maps and institutional affiliations.

Copyright: (c) 2021 by the authors. Licensee MDPI, Basel, Switzerland. This article is an open access article distributed under the terms and conditions of the Creative Commons Attribution (CC BY) license (https:// creativecommons.org/licenses/by/ $4.0 /)$.

\begin{abstract}
Studies of the effectiveness of multimedia cartography products may include mini-map design for navigation. In this study, we have touched upon designing gameplay to indicate the impact of the mini-map on the time effectiveness of a player that can walk or teleport himself/herself along marked out points in virtual topographic space. The eye-tracking examination of gamers' effectiveness in a non-complex game of collecting coins in a reconstructed stronghold on the holm provided us with a new perspective on the role of mini-maps. The more time gamers took to examine the mini-map, the more time they needed to finish the game, thus decreasing their effectiveness. The teleporting gamers had significantly higher time effectiveness than walking gamers, however, the data obtained showed only a minor difference between the proportions of the mini-map examination time to the total game time for walking and teleportation.
\end{abstract}

Keywords: mini-map; virtual stronghold; walking; teleportation; multimedia cartography; medium effectiveness; Unity; topographical space; gamer; gameplay; eye tracking

\section{Introduction}

To boost the usefulness of a map, one traditionally employs a location map, i.e., a map on a smaller scale that presents the geographical location of the area covered by the topographic map with reference to a larger administrative unit or physio-geographical unit $[1,2]$. The location map helps in geographical orientation at a more general level than the more detailed topographic map [3]. The concept of topographic orientation is related to the use of topographic maps directly in the field $[4,5]$. The content of topographic maps is compared to objects in the field to evaluate their actual location and spatial relationships (i.e., directions and distances) between them. In this study, the principles of cartographic design, especially layout construction, are of great importance. The layout includes the main, largest frame of cartographic content along with other frames of the map, with the legend being placed ideally on the right-hand side of the cartographic content or at the bottom of the map [6,7]. Global websites commonly use maps with mini-maps for car and pedestrian navigation. Their interface is evolving towards higher intuitiveness and quick navigation [8].

Navigation in a 3D computer game environment constitutes an essential element of the gameplay. Almost all the games use mini-maps to facilitate the character's movement in the game and the use of a virtual interface $[9,10]$. The mini-map has become standard not only in popular computer games with the open world, but also in visualizations and VR games (VR-Virtual Reality) [11-15]. The knowledge of the game space, one's location and individual stages of tasks may drastically change the chances of victory [16-19]. As suggested by game designers, mini-maps generally should not exceed $10 \%$ of the available display area [20]. Additionally, mini-maps are sometimes referred to as a "corner map", although their display position is not standardized [21]. Walking is the most immersive 
locomotion technique in the movement around geographic space [22,23]. Multiple VR games that focus on the movement around virtual space employ walking at a natural pace $[15,24,25]$. Teleportation from one point to another by means of the hand-held controller, which significantly accelerates the movement in geographical space, is becoming increasingly popular in VR games [23,26-28].

The study of the effectiveness and attractiveness of multimedia cartography products may include subjective opinions of users, formulated in a descriptive way or in the form of specific marks $[15,29,30]$. Speed and/or correctness of task performance or interpreting the information about geographic phenomena constitute part of the objective characteristics of geomedia products that determine the effectiveness of use [31-37]. The speed of performing the spatial task with the use of the appropriate interactive tool is the most measurable factor of effectiveness. The effectiveness of multimedia cartography products is studied by means of: online questionnaires, directly supervised questionnaires, tasks performed in the field with the help of mobile devices, direct observations, observations with remote recording of the participant's movement and observations via eye tracking [36,38-42]. Homogenous groups of respondents with the proper number of representatives, e.g., 15-30 students or 5-15 experts per one respondent group, are usually invited to participate in research $[15,36,43]$. In multimedia cartography, statistical correlations are taken into consideration if homogeneous respondent groups participate in the research. For instance, the Spearman test is used to indicate the correlation between the respondents' answers and the times taken for tasks [36].

Designing mini-maps for navigation during walking and teleportation requires specific theoretical and technological procedures. The problem of the complementary employment of cartographic design rules with IT (information technology) notations (i.e., 3D topographic space and gameplay interaction with the possibility of recording the gamer's effectiveness by the method of eye tracking) has not been examined to date by any studies dealing with the effectiveness of multimedia cartography products.

In this analysis, we consider effectiveness as the total virtual game time of a single player, which means that the player that moves from the first to the last point faster is more effective. Thus, we touch upon designing gameplay to indicate the impact of the mini-map on the time effectiveness of a player that can walk or teleport himself/herself along marked out points in virtual topographic space.

The rest of the article is structured as follows. Section 2 presents the major aim and specific questions of the article analysis. In Section 3, we introduce our methodology for designing a VR application and experimental research process. Section 4 provides details of the experimental evaluation. Finally, in Section 5, we discuss the results and present our conclusions.

\section{Aim and Questions}

Considering complexity, different approaches to defining the concept, multiple possibilities of testing multimedia effectiveness and many other factors considered in various studies, we decided to focus on time effectiveness in virtual space as the most important factor. The major aim of the analysis is to examine the significance of mini-maps for the time effectiveness of a player walking around and teleporting in the virtual topographic space. Apart from this aim, we have also asked the following specific questions:

- What are the differences between the times of individual gameplay by walking and teleporting players, respectively?

- What impact does the mini-map examination time have on the total game time for walking and teleportation?

- What is the correlation between the mini-map examination time and the total game time while collecting the first coin and the last coin?

- Does complementary cartographic and IT game design in topographic space with mini-maps allow one to evaluate the gamer's effectiveness in the game? 


\section{Methodology}

To meet the objective and answer the above questions, we have adopted four main research stages:

- To pinpoint the conceptual assumptions (Section 3.1);

- To create a game in a virtual stronghold following a scheme and a geographical layout of the gameplay elements (Section 3.2, Figures 1,3 and 5);

- To prepare and carry out surveys among walking and teleporting players (Section 3.3, Figures 2 and 4$)$.

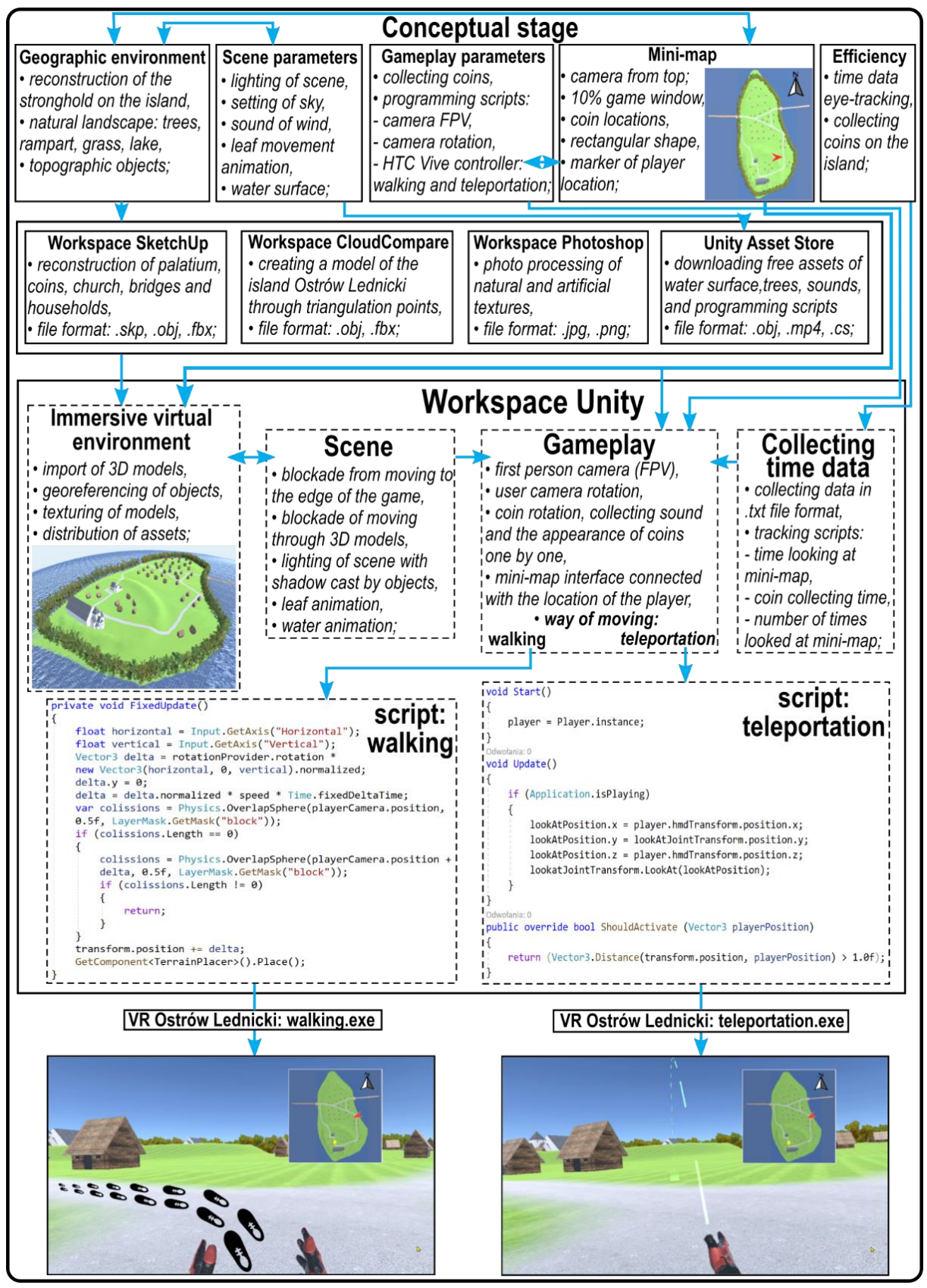

Figure 1. Scheme of working out the VR application for two game versions: with walking and teleportation. 


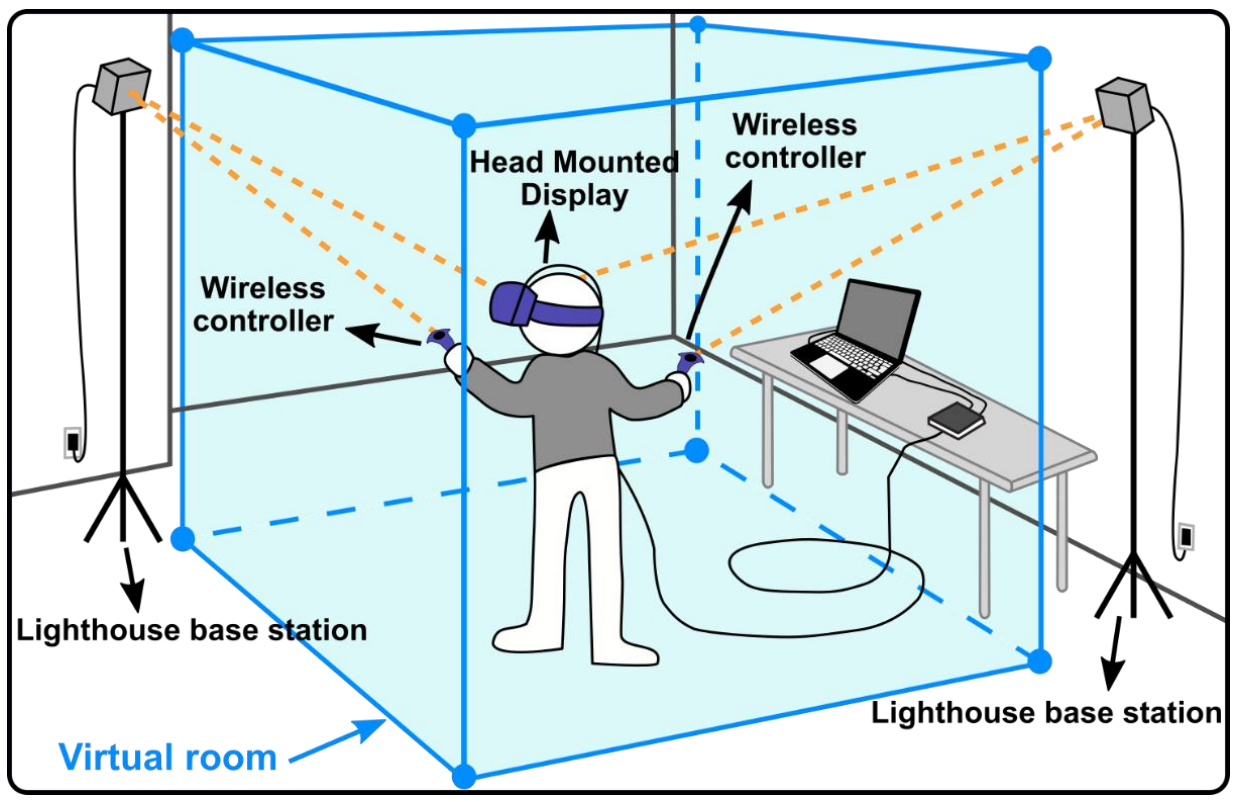

Figure 2. Equipment and room installation progress with HTC goggles (based on https:www.vive. com, accessed on 20 February 2021).

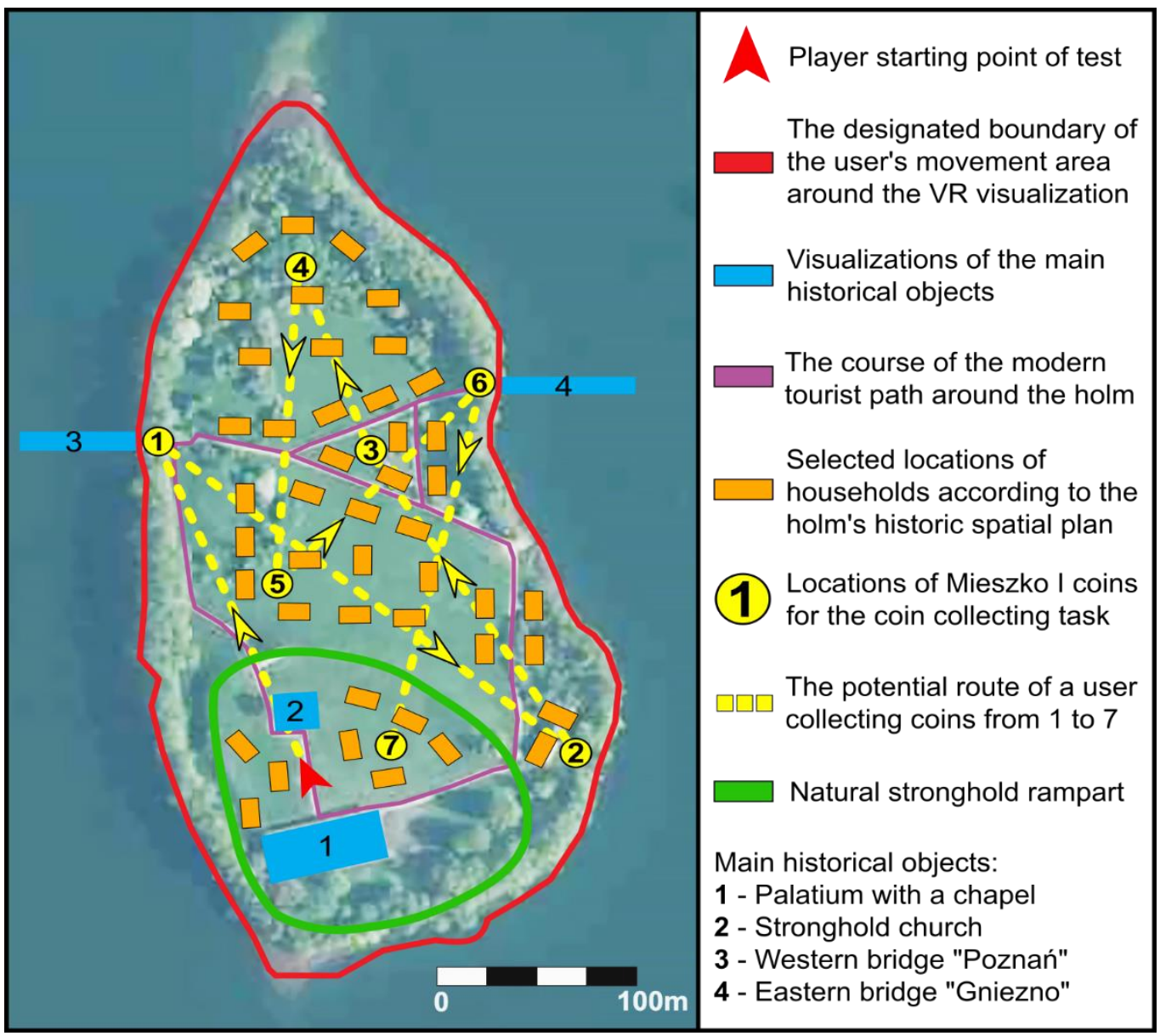

Figure 3. Layout of the application with the placement of individual game elements on the holm. 


\subsection{Concept}

Considering the cartographico-geographic attitude (cartographic design of topographic space and mini-maps), gamers' habits (typical game actions) and IT aspects (software in game engines), we adopted a concept embracing the following assumptions:

- Type of multimedia application: VR coin collecting game in specified locations in a small, limited, topographic space, which is possible to present in a single mini-map view;

- Multimedia design: the geographic part (creating the island's topography), the cartographic part (designing the trail and the mini-map) and the IT part (designing the game and eye tracking);

- Medium: full-immersive VR-presence and movement, supported with sound and animated effects;

- Software and equipment: graphic software (Photoshop), architectural software (SketchUp), geographical modeling software (CloudCompare), game engine (Unity), survey (HTC Vive Pro Eye goggles and HTC controllers);

- Technological process: managing transformation and data integration in a geomatic process in several workspaces;

- Geographic space: stronghold on the island, elements of natural landscape (trees, rampart, grass, lake) and historical buildings (church, palace, huts, bridges);

- Parameters of the scene: natural lighting, cloudless sky, sounds of wind, animation of leaves and water surface;

- Parameters of the gameplay: collecting coins, programming scripts, programming HTC Vive controllers for two types of movement: walking and teleportation;

- Mini-map: the view of the entire island in the stronghold's graphics; $10 \%$ of the game window view; in the right top corner; location of coins marked with yellow dots; northern orientation, rectangular shape; gamer's location indicated by the red arrow pointing to the direction of looking;

- Parameters of effectiveness: collecting time data scripts; individual and synthetic analysis; analysis of gamers' effectiveness;

- Respondents: screen-based video game users; lacking experience in immersive VR environments; playing a minimum of $10 \mathrm{~h}$ per week;

- The way of conducting the research: each gamer stays in the virtual room; eye calibration of the position of goggles and controllers; eye-tracking study with HTC goggles; the same task for each gamer: to collect 7 coins, time for the task: approximately 15 min; obtaining data on the total game time and the mini-map examination time;

- Expected research results: statistical and graphic specification of time effectiveness of a gamer that walks and teleports by means of the mini-map.

\subsection{Creating a VR Application}

The planned VR application was created as a part of four workspaces according to the following order situated in the scheme in Figure 1. According to Medyńska-Gulij [6], a workspace is an area in the application (i.e., digital work environment dedicated to the specific application) that allows one to perform digital operations (framing, cutting, rotation, adding points, georeferencing) for various data types (raster and vector) and formats (.png, .svg, .obj, .shp), operating on both desktop and mobile systems according to the interface and programming scripts.

It is worth mentioning that in the research, we used a virtual presentation of the stronghold on the holm of Ostrów Lednicki (Poland) worked out in four workspaces: SketchUp, CloudCompare, Photoshop and Unity. Hence, we would like to focus specifically on cartographic design (mini-maps), GIS design (scene and gameplay for walking and teleportation) and IT design (scripts allowing one to obtain time data during the eyetracking study) [15].

Cartographic attitude included the design and creation of the geographic space of the stronghold, with preservation of its natural topography, and designing a mini-map. The 
IT attitude encompassed the implementation of programming scripts for the game and programming scripts that allowed one to collect time data for the eye-tracking examination.

The first stage of design in Unity was to import a 3D model of natural relief and a georeference of modeled historical objects and to add landscape assets and task coins (Figure 3). Then, individual scene parameters were worked out, following the initially assumed concept. Box colliders were implemented at both ends of the holm, and several of them were also used to prevent the gamers from walking through the building walls, to create the realistic space of the holm. Scene light was directed toward the north to make shadows of objects and create a natural 3D impression of the holm landscape. Leaves and the surface of the water were animated, and wind sounds, as well as footstep sounds, were added to boost the gamers' level of immersion.

To make the design of a rectangular mini-map reflect the space of the holm as seen from a pedestrian's point of view, we used an extra camera for the bird's eye view (Figure 3). Following the cartographic rules, the mini-map was north-oriented and received a north arrow. Using the "Canvas" object (the area inside of which all user interface elements should be), the mini-map was set in the top right corner of the gamers' view. The position of the gamer is represented by the red arrow, and the location of the next coin to be collected is symbolized by the yellow ring. In this study, the character is not bound to the center of the map field. The animated symbol representing a player constantly changes its position on the mini-map, and the map always includes the same reference objects (world-oriented mini-map) [20].

SteamVR, a Unity plugin, was responsible for the main interface between the gamer and the virtual stronghold. The plugin solves the problem of configuring the first-person camera in such a way that it displays a reliable view in goggles adapted to different perspectives from both eyes. Additionally, it includes ready implementation of the reflection of the gamer's head and hands in the world and facilitates programming behaviors related to the use of the touch panel and controller buttons.

The next step was to write programming scripts needed for the correct operation of the game and the development of conceptual assumptions (Figure 5). "CoinController", responsible for presenting the coin by rotating it and creating audio-visual effects on collection, was the first script to be written. It was also responsible for managing the order in which the coins appeared, and it also logged the time of coin collection for further processing. The next script was "GazeMonitor", which checked whether the object was in the center of the player's vision. Its functionality was supplied by eye tracking and the Tobii plugin. Tobii XR SDK for Unity offers simple add-on-independent HTC Vive Pro Eye methods of accessing eye-tracking data and tools for scene development. The following scripts "MinimapMarkerController" and "MinimapMarkerSpawner" were responsible for creating and controlling mini-map markers for the position of the gamer and coins. While the script responsible for navigating through the teleportation was included in the SteamVR plugin, the script responsible for walking in geographic space had to be rewritten from scratch. The script "PlayerController", depicted in Figure 5, was responsible for the user's walking and collisions with buildings. The "TerrainPlacer" script, responsible for aligning objects to relief elements, was used to glue not only buildings but also coins and the player to the ground. The next step of the correct operation of the "PlayerController" script was to write the "TrackPad" script, which was responsible for collecting and storing HTC controller trackpad touch data. The walking speed option with the controller was set to 4.8 meters per second to represent the natural movement in virtual terrain and to match the speed of movement through teleportation. HTC documentation shows that the distance of teleporting with a controller is a maximum of 45 degrees of a parabolic arc from the player's elevation of the controller.

The last step in the IT approach was to create a package of scripts that would be responsible for collecting time and eye-tracking data (Figure 5). The first script was "SimData Manager", responsible for enabling other scripts to log events, collect data and process collected data into a readable TXT log file. This manager was accompanied by 
models, i.e., scripts that contain only data structures and have no behavior. "SimData" was such a model and it contained a collection of "Event" entries and a list of "SimDataUnit" records. The "Event" model was supposed to contain the information about the user's action, or a specific system-generated event at a specific time, such as coin collection. Another model, "SimDataUnit", was responsible for storing a temporary simulation status contained within one frame at a specific time.

Eventually, after all operations, the created applications were exported. The walking.exe application, including the way of moving by holding the touchpad, and teleportation.exe, including teleportation by clicking on the touchpad, were exported.

\subsection{Participants and Experimental Process}

We invited 40 game users, selected at random among students, who declared to spend over $10 \mathrm{~h}$ per week on screen games but lacking any experience with VR games, to participate in the research. Twenty game users collected coins by means of teleportation, and the other half by walking around the holm. Game users, aged 17-26, participated in the game voluntarily, without any financial gratification, and could resign from further gameplay at any moment.

The research was conducted on a laptop with Windows 10 and two applications created in Unity: walking.exe and teleportation.exe (Figure 1). To carry out the research, we used HTC Vive Pro Eye goggles with a definition of $2880 \times 1600$ px. In Steam VR, we prepared a virtual room for the gamer, configured the laser tracking of base stations for establishing the position of goggles and controllers and calibrated the floor's position (Figure 2). To capture the gamer's gaze, we used the in-built device for eye tracking in the HTC goggles.

Before each gamer put on VR goggles, he was informed that after putting them on, he would find himself in the virtual medieval stronghold on the holm (Figure 4). The gamer was informed how to set the focus in the VR goggles and how to use the wireless controllers. Then, each gamer was introduced to the main goal of the game, which was to collect seven coins. Each of them appeared on the mini-map in the form of a yellow dot, whereas their location was marked with a red arrow pointing in the direction the gamer was looking.

After putting on the goggles, the gamer confirmed that he had moved to the virtual stronghold, could hear sounds and understood the functioning of the controllers, as well as could see his own location on the mini-map. The confirmation by the gamer that he had started to move towards the first coin noticed on the mini-map initiated measuring the total game time (START in Figure 4), and collecting the 7th coin ended measuring the game time (Figure 4 ).

\section{Results}

Obtained time data were placed in two tables: walking gamers (Table 1) and teleporting gamers (Table 2). Data in tables were divided into three major data categories: total time, individual time - from the start to the collection of the first coin-and individual timefrom the collection of the 6th coin to the collection of the 7th coin. For each category, we distinguished the three most significant data subcategories for each type of movement: timeWalking-Space (tWS) - the total game time for walking gamers, time-Teleportation-Space (tTS) - the total game time for teleporting gamers, time-Walking-Mini-map (tWM) — the mini-map examination time for walking gamers, time-Teleportation-Mini-map (tTM) — the mini-map examination time for teleporting gamers and $\mathrm{tWM} / \mathrm{tWS}$ and $\mathrm{tTM} / \mathrm{tTS}$, i.e., the ratio in percent. To present the data from Tables 1 and 2, we used column charts and a line chart (Figures 6 and 7). 
Table 1. Time data for walking (20 gamers). The total game time for walking gamers-tWS (time-Walking-Space), the mini-map examination time for walking gamers-tWM (time-Walking-Mini-map).

\begin{tabular}{|c|c|c|c|c|c|c|c|c|c|}
\hline \multirow[b]{2}{*}{ Id } & \multicolumn{3}{|c|}{ A. Total Time-Walking } & \multicolumn{3}{|c|}{$\begin{array}{c}\text { B. Individual Time } \\
\text { (Start-1 Coin)-Walking }\end{array}$} & \multicolumn{3}{|c|}{$\begin{array}{l}\text { C. Individual Time } \\
\text { (6-7 Coins)-Walking }\end{array}$} \\
\hline & tWS: & tWM: & tWM/tWS: & $t_{1} W S:$ & $\mathbf{t}_{1} \mathbf{W M}:$ & $t_{1} W M / t_{1} W S:$ & $t_{2} W S:$ & $t_{2} W M:$ & $t_{2} W M / t_{2} W S:$ \\
\hline 1 & 353.2 & 177.9 & $50 \%$ & 56.8 & 16.3 & $29 \%$ & 56.0 & 27.6 & $49 \%$ \\
\hline 2 & 419.0 & 208.6 & $50 \%$ & 59.6 & 29.0 & $49 \%$ & 80.1 & 47.0 & $59 \%$ \\
\hline 3 & 386.5 & 181.0 & $47 \%$ & 87.5 & 41.8 & $48 \%$ & 54.5 & 19.9 & $36 \%$ \\
\hline 4 & 453.4 & 178.7 & $39 \%$ & 79.7 & 20.0 & $25 \%$ & 68.4 & 25.2 & $37 \%$ \\
\hline 5 & 544.8 & 208.5 & $38 \%$ & 64.1 & 6.7 & $10 \%$ & 67.6 & 38.1 & $56 \%$ \\
\hline 6 & 530.4 & 200.3 & $38 \%$ & 71.5 & 17.7 & $25 \%$ & 67.4 & 32.8 & $49 \%$ \\
\hline 7 & 377.0 & 130.7 & $35 \%$ & 55.7 & 8.3 & $15 \%$ & 55.6 & 29.7 & $53 \%$ \\
\hline 8 & 392.7 & 129.4 & $33 \%$ & 65.6 & 19.2 & $29 \%$ & 59.0 & 18.8 & $32 \%$ \\
\hline 9 & 380.1 & 119.5 & $31 \%$ & 59.7 & 13.4 & $22 \%$ & 54.5 & 16.5 & $30 \%$ \\
\hline 10 & 371.0 & 113.8 & $31 \%$ & 59.2 & 13.2 & $22 \%$ & 60.2 & 21.0 & $35 \%$ \\
\hline 11 & 393.2 & 108.7 & $28 \%$ & 49.8 & 13.2 & $27 \%$ & 80.5 & 20.9 & $26 \%$ \\
\hline 12 & 375.3 & 100.3 & $27 \%$ & 69.4 & 13.8 & $20 \%$ & 54.5 & 18.1 & $33 \%$ \\
\hline 13 & 412.4 & 110.2 & $27 \%$ & 56.2 & 8.1 & $14 \%$ & 81.9 & 25.9 & $32 \%$ \\
\hline 14 & 366.6 & 94.3 & $26 \%$ & 62.8 & 10.6 & $17 \%$ & 59.6 & 17.8 & $30 \%$ \\
\hline 15 & 378.8 & 91.4 & $24 \%$ & 66.8 & 12.8 & $19 \%$ & 60.1 & 15.6 & $26 \%$ \\
\hline 16 & 499.2 & 114.3 & $23 \%$ & 77.8 & 8.0 & $10 \%$ & 67.3 & 24.2 & $36 \%$ \\
\hline 17 & 349.2 & 59.6 & $17 \%$ & 61.6 & 8.8 & $14 \%$ & 56.1 & 7.9 & $14 \%$ \\
\hline 18 & 302.3 & 49.7 & $16 \%$ & 49.4 & 5.9 & $12 \%$ & 49.2 & 8.7 & $18 \%$ \\
\hline 19 & 389.2 & 60.0 & $15 \%$ & 66.6 & 6.2 & $9 \%$ & 66.0 & 11.4 & $17 \%$ \\
\hline 20 & 379.0 & 56.2 & $15 \%$ & 55.0 & 5.4 & $10 \%$ & 88.9 & 11.2 & $13 \%$ \\
\hline Median & 383.3 & 114.0 & $29 \%$ & 62.2 & 13.0 & $19 \%$ & 60.2 & 20.4 & $33 \%$ \\
\hline
\end{tabular}

Table 2. Time data for teleportation (20 gamers). The total game time for teleporting gamers-tTS (time-Teleportation-Space), the mini-map examination time for teleporting gamers—tTM (time-Teleportation-Mini-map).

\begin{tabular}{|c|c|c|c|c|c|c|c|c|c|}
\hline \multirow[b]{2}{*}{ Id } & \multicolumn{3}{|c|}{ A. Total Time-Teleportation } & \multicolumn{3}{|c|}{$\begin{array}{l}\text { B. Individual Time } \\
\text { (Start-1 Coin)-Teleportation }\end{array}$} & \multicolumn{3}{|c|}{$\begin{array}{l}\text { C. Individual Time } \\
\text { (6-7 Coins)-Teleportation }\end{array}$} \\
\hline & tTS: & tTM: & tTM/tTS: & $\mathbf{t}_{1} \mathrm{TS}:$ & $\mathbf{t}_{1}$ TM: & $\mathbf{t}_{1} \mathrm{TM} / \mathrm{t}_{1} \mathrm{TS}:$ & $t_{2}$ TS: & $t_{2}$ TM: & $t_{2} T M / t_{2} T S:$ \\
\hline 1 & 201.5 & 79.2 & $39 \%$ & 32.6 & 5.4 & $17 \%$ & 19.7 & 12.4 & $63 \%$ \\
\hline 2 & 218.4 & 77.9 & $36 \%$ & 45.5 & 8.1 & $18 \%$ & 30.5 & 14.2 & $47 \%$ \\
\hline 3 & 273.3 & 96.5 & $35 \%$ & 42.0 & 16.4 & $39 \%$ & 44.2 & 11.8 & $27 \%$ \\
\hline 4 & 148.5 & 52.0 & $35 \%$ & 27.1 & 10.9 & $40 \%$ & 24.5 & 6.3 & $26 \%$ \\
\hline 5 & 365.1 & 123.0 & $34 \%$ & 74.6 & 19.7 & $26 \%$ & 55.3 & 27.6 & $50 \%$ \\
\hline 6 & 164.7 & 55.3 & $34 \%$ & 34.9 & 7.9 & $23 \%$ & 15.5 & 5.8 & $37 \%$ \\
\hline 7 & 166.3 & 55.6 & $33 \%$ & 26.3 & 12.8 & $49 \%$ & 24.9 & 6.5 & $26 \%$ \\
\hline 8 & 323.9 & 106.8 & $33 \%$ & 44.5 & 10.9 & $24 \%$ & 44.4 & 21.5 & $48 \%$ \\
\hline 9 & 222.2 & 73.0 & $33 \%$ & 39.3 & 18.7 & $48 \%$ & 25.6 & 10.0 & $39 \%$ \\
\hline 10 & 196.6 & 60.7 & $31 \%$ & 32.9 & 4.5 & $14 \%$ & 33.6 & 13.6 & $41 \%$ \\
\hline 11 & 302.2 & 93.0 & $31 \%$ & 31.0 & 5.2 & $17 \%$ & 64.0 & 23.8 & $37 \%$ \\
\hline 12 & 418.6 & 123.6 & $30 \%$ & 50.0 & 19.7 & $39 \%$ & 38.5 & 24.4 & $63 \%$ \\
\hline 13 & 213.8 & 63.1 & $30 \%$ & 37.7 & 11.6 & $31 \%$ & 27.3 & 9.8 & $36 \%$ \\
\hline 14 & 268.3 & 77.4 & $29 \%$ & 33.0 & 2.9 & $9 \%$ & 60.7 & 25.8 & $43 \%$ \\
\hline 15 & 315.8 & 87.2 & $28 \%$ & 48.9 & 14.0 & $29 \%$ & 33.8 & 5.6 & $17 \%$ \\
\hline 16 & 203.9 & 56.3 & $28 \%$ & 30.2 & 9.7 & $32 \%$ & 25.3 & 4.7 & $18 \%$ \\
\hline 17 & 331.7 & 81.1 & $24 \%$ & 49.9 & 8.9 & $18 \%$ & 47.3 & 9.0 & $19 \%$ \\
\hline 18 & 237.1 & 38.8 & $16 \%$ & 33.9 & 4.7 & $14 \%$ & 27.6 & 6.0 & $22 \%$ \\
\hline 19 & 255.2 & 41.6 & $16 \%$ & 47.5 & 5.6 & $12 \%$ & 28.4 & 6.2 & $22 \%$ \\
\hline 20 & 331.5 & 48.6 & $15 \%$ & 31.2 & 5.5 & $18 \%$ & 62.8 & 5.6 & $9 \%$ \\
\hline Median & 246.2 & 75.2 & $31 \%$ & 36.3 & 9.3 & $24 \%$ & 32.0 & 9.9 & $37 \%$ \\
\hline
\end{tabular}




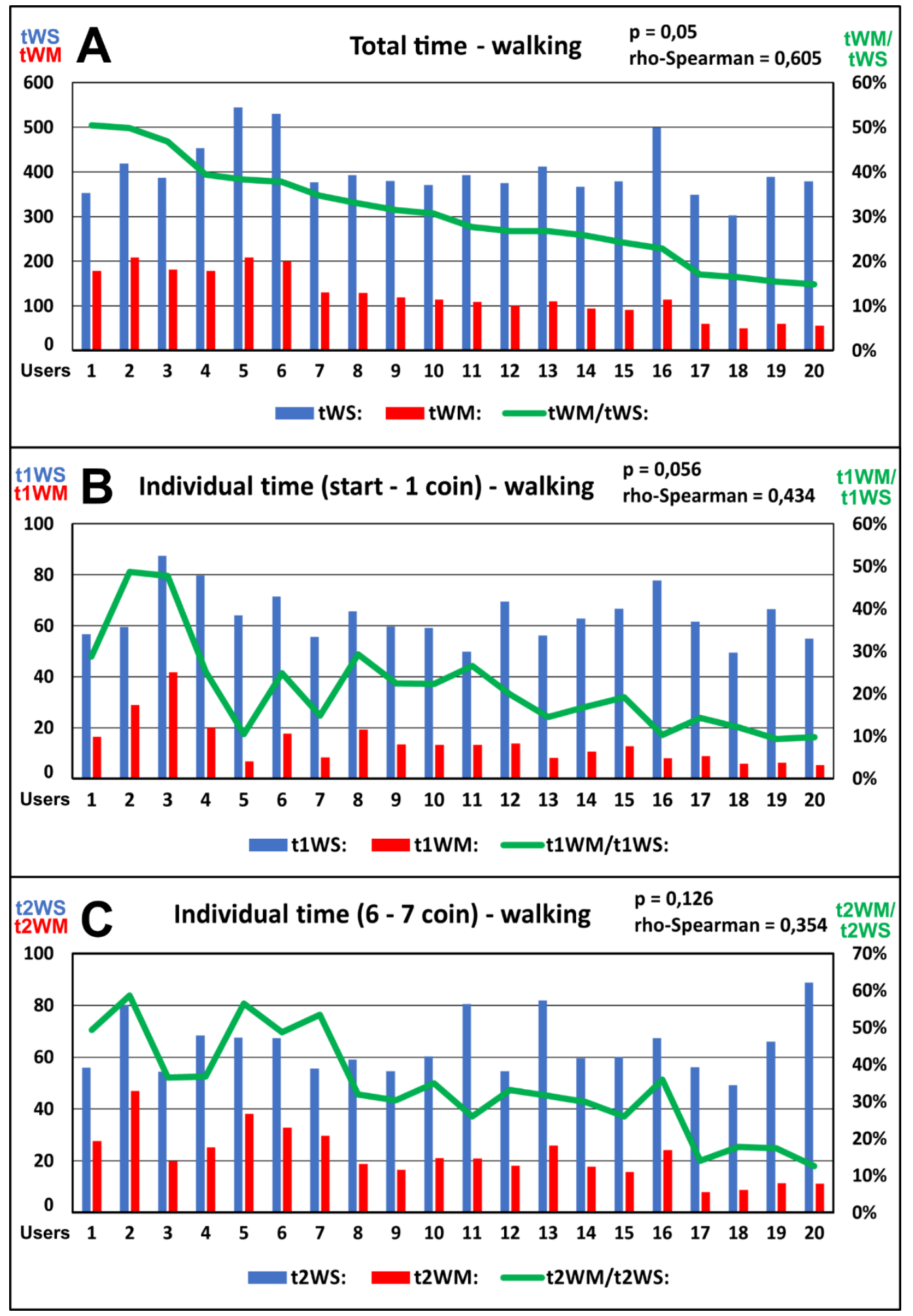

Figure 6. Visualization of time data for walking. 


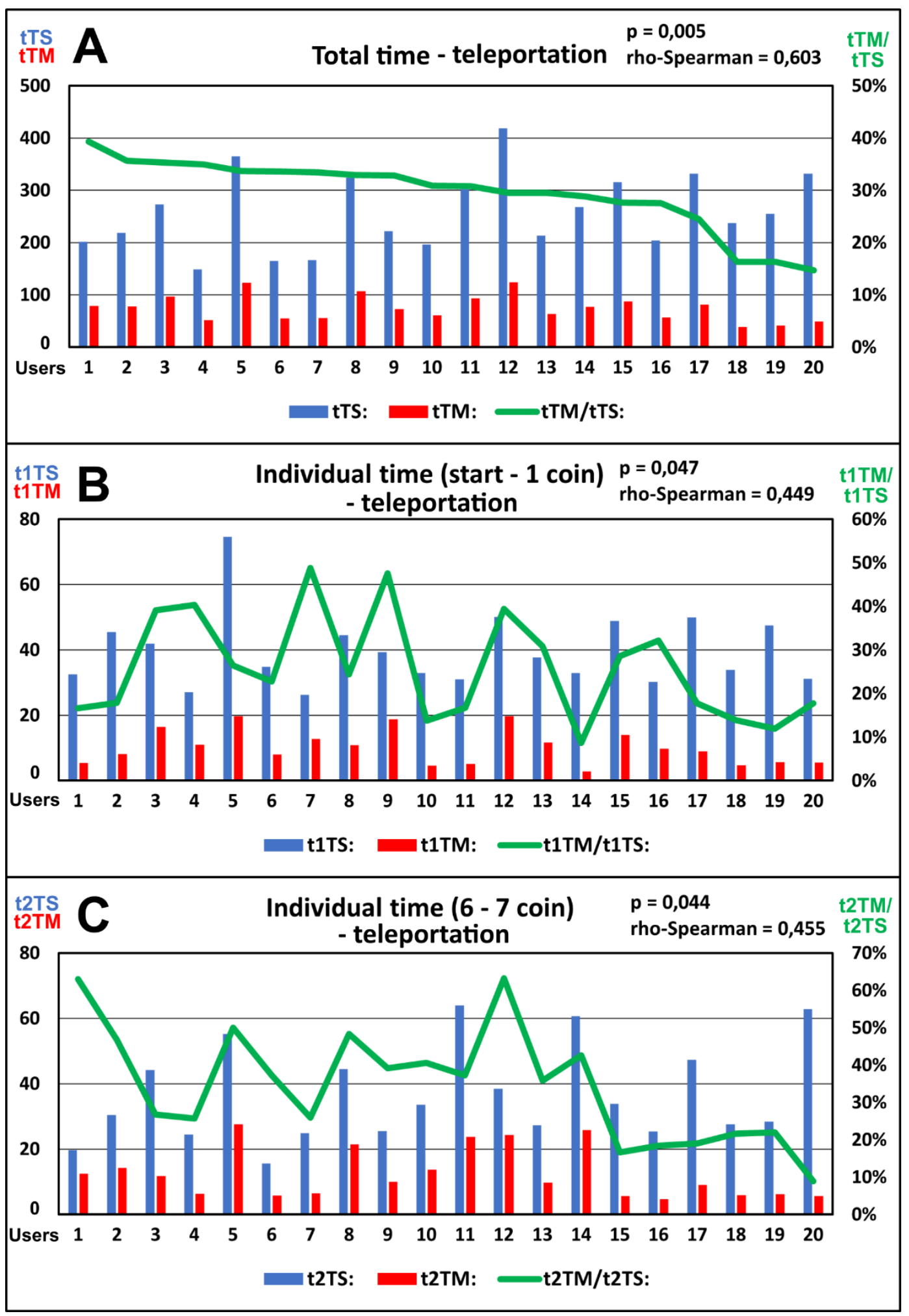

Figure 7. Visualization of time data for teleportation.

In analytical comparisons, we wanted to demonstrate the level of time effectiveness in individual games. Effectiveness is understood as the total game time achieved by a single gamer. In this research, a gamer that needs less time to collect all the coins has greater effectiveness. 
In the analysis of numerical data, we assumed that the measurements of the mini-map examination time that are below $0.3 \mathrm{~s}$ and appeared after collecting any coins until the next correct mini-map examination time measurement that exceeded $0.3 \mathrm{~s}$ would be deleted. For a middle-aged person, the reaction time is around $0.2-0.4 \mathrm{~s}$, hence, we rounded the number down, as multiple young people participated in the research [44]. Errors may have resulted from the incorrect refreshing of display frames during teleportation or too rapid head movements. We recorded a dozen or so such erroneous time measurements.

We sorted out the results for walking gamers, with the greatest ratio of mini-map examination time to the total game time (Table 1 ) as our point of reference. Gamer 5 had the longest total game time (544.8 s), and gamer 18 had the shortest (302.3 s) (Table 1A). The time difference was $242.5 \mathrm{~s}$, which equals an effectiveness discrepancy of $55 \%$ between the two gamers. The average total game time (the median) for the entire group was $383.3 \mathrm{~s}$, which marks the average effectiveness level for walking gamers. Comparing the shortest and the longest time to the median, gamer 18 showed an effectiveness increase of $21 \%$ $(81.0 \mathrm{~s})$, whereas gamer 5 showed an effectiveness decrease of $42 \%$ (161.5 s).

The longest mini-map examination time was recorded for gamer $2(208.6 \mathrm{~s})$, and the shortest for gamer 18 (49.7 s) (Table 1A). For most of the walking users, the ratio of the total mini-map examination time to the total game time exceeded $25 \%$, which means that over $\frac{1}{4}$ of their total walking time was spent on looking at the navigation tool. Collecting the first coin was easier for most gamers without the excessive use of the mini-map (15 gamers below $25 \%$ ), whereas collecting the last coin required longer examination of the mini-map (16 gamers above $25 \%$ ).

When coming up to the first coin, gamer 3 was the one that examined the mini-map the longest (41.8 s), and gamer 20 the shortest (5.4 s) (Table 1B). At the end of the task, right before collecting the last coin, gamer 2 took the most time to examine the mini-map ( $47.0 \mathrm{~s}$ ), and gamer 17 the least (7.9 s) (Table 1C). A significant majority of walking users examined the mini-map longer at the last coin than at the first one, even though the average time of completing the task was comparable. Only gamers 3,8 and 17 took more time prior to the first coin and less time prior to the last coin, which means that only these three gamers, despite similar total game time, similar route and obstacles in the form of the rampart and buildings, had higher effectiveness of using the mini-map during the game.

To examine the correlation between the total game time and the mini-map examination time, we used the Spearman correlation test. There is a correlation between the use of the mini-map and the total game time $(\mathrm{r}=0.605)$ (Figure $6 \mathrm{~A})$, however, only for the first diagram. This means that the more walking users used the mini-map during the game, the more time they needed for collecting all coins.

The results of teleporting gamers were sorted out, using the largest ratio of the minimap examination to the total game time as a point of reference (Table 2). Gamer 12 was the one with the longest total game time (418.6 s), and gamer 4 had the shortest (148.5 s) (Table 2A). The time difference is $270.1 \mathrm{~s}$, which gives a disparity of $35 \%$ between game users. The average total game time for the entire group was $246.2 \mathrm{~s}$, which constitutes the average effectiveness level for teleporting gamers. Comparing the shortest and the longest time to the median, gamer 4 showed an effectiveness increase of $40 \%(97.6 \mathrm{~s})$, and gamer 12 showed an effectiveness decrease of $70 \%$ (172.5 s).

The longest mini-map examination time was registered for gamer 12 (123.6 s), and the shortest for gamer 18 (38.8 s) (Table $2 \mathrm{~A}$ ). For a significant majority of teleporting gamers, the ratio of the total mini-map looking time to the game finishing time was higher than $25 \%$ but did not exceed $40 \%$, which means that they spent over $\frac{1}{4}$ of their time looking at their location and the location of coins. Collecting the first coin for almost half of the game users was quicker when they did not use the mini-map for too long (11 gamers below 25\%), whereas collecting the last coin seemed more difficult and required longer examination of the mini-map (14 people above $25 \%$ ).

Gamers 5 and 12 needed the most time to examine the mini-map (19.7s), and gamer 14 the least time ( $2.9 \mathrm{~s})$ (Table 2B). During the last walk, gamer 5 needed the most time to 
look at the mini-map (27.6 s), and gamers 15 and 20 the least time (5.6 s) (Table 2C). During teleportation, most gamers took more time to look at the mini-map when collecting the last coin, compared to the time they took when collecting the first coin.

According to the Spearman correlation test for the first diagram, there is a significant correlation between the use of the mini-map and the total game time $(r=0.603)$ (Figure 7A). This shows that gamers using the mini-map for longer during the game needed more time to collect all coins. The second and third diagram depict similar correlations, however, they have lower statistical power (Figure 7B,C), which means that for collecting the first and the seventh coin, the more time the gamer took to examine the mini-map, the longer it took for him to finish the game.

To assess the effectiveness of walking and teleportation users, we juxtaposed the medians for individual categories in Table 3, and in diagrams in Figure 8. Walking gamers needed significantly more time to finish the game (383.3 s) than teleporting gamers $(246.2 \mathrm{~s})$ (Table $3 \mathrm{~A}$ ). When the game concept was created, it was assumed that the walking speed was $4.8 \mathrm{~m} / \mathrm{s}$, in accordance with the natural feeling of the gamer's movement in topographic space. Reading the default teleportation settings by HTC, one can observe that the maximum teleportation distance depends on the movement of the controller by the gamer (with a maximum of 45 degrees of a parabolic arc).

Table 3. Comparison of the median time for walking and teleportation.

\begin{tabular}{|c|c|c|c|c|c|c|c|c|c|}
\hline & \multicolumn{3}{|c|}{ A. Median for Total Time } & \multicolumn{3}{|c|}{$\begin{array}{l}\text { B. Median for Individual } \\
\text { Time (Start-1 Coin) }\end{array}$} & \multicolumn{3}{|c|}{$\begin{array}{l}\text { C. Median for Individual } \\
\text { Time (6-7 Coins) }\end{array}$} \\
\hline Id & tS: & tM: & tM/tS: & $t_{1} S:$ & $\mathbf{t}_{1} \mathbf{M}:$ & $t_{1} M / t_{1} S:$ & $t_{2} S:$ & $\mathbf{t}_{2} \mathbf{M}:$ & $t_{2} M / t_{2} S:$ \\
\hline Walking & 383.3 & 114.0 & $29 \%$ & 62.2 & 13.0 & $19 \%$ & 60.2 & 20.4 & $33 \%$ \\
\hline Teleportation & 246.2 & 75.2 & $31 \%$ & 36.3 & 9.3 & $24 \%$ & 32.0 & 9.9 & $37 \%$ \\
\hline
\end{tabular}

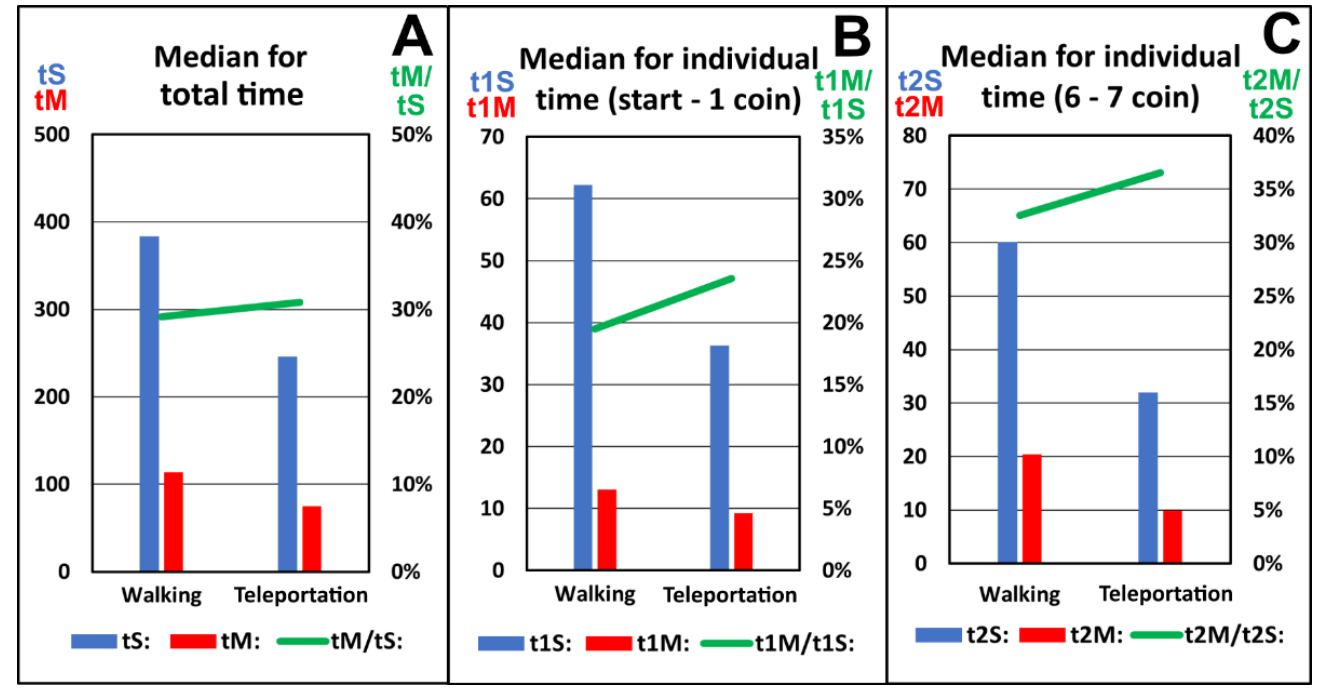

Figure 8. Comparative visualization of time for walking and teleportation.

The comparison of two medians of the total game time reveals that the difference is $137.1 \mathrm{~s}$, which means that the teleporting gamers were $36 \%$ more effective than the walking gamers. In proportion to the total game time, the mini-map examination time was also longer for walking (114.0 s) than for teleportation (75.2 s) (Table 3A). Juxtaposing the proportion of the mini-map examination time to the total game time, one can conclude that these proportions are highly similar, i.e., 31\% for teleporting gamers and $29 \%$ for walking gamers. The difference of $2 \%$ constitutes around $3 \mathrm{~s}$, which demonstrates just a minor difference between gamers. Both walking and teleporting gamers took significantly more time to use the mini-map while collecting the last coin $(33 \%$ and $37 \%)$ than while collecting the first one (19\% and $24 \%$ ) (Table 3B,C). 


\section{Discussion and Conclusions}

Generally speaking, it can be said that the analysis of gamers' time effectiveness in a non-complex game of collecting coins in the reconstructed stronghold on the holm provided us with a new perspective on the role of mini-maps in movement in virtual topographic space.

Complementary cartographic and IT design employed in the research is, in the case of VR with mini-maps, consistent with the rules of map design that have always been determined by the technology of publishing maps and other products of multimedia cartography. We designed a game in the closed space of the holm with a relatively small number of topographic objects in such a way that the gamer walks the previously used paths on his way to the next coin. Such a strategy was supposed to accustom the gamer to the virtual topographic space. Each coin was situated in such a place that the gamer could not see it immediately after obtaining the previous one, which resulting in him having to use the mini-map.

The appearance, location and size of the mini-map became a problem in the concept of cartographic design. A traditional location map has generalized content, compared to the highly detailed main cartographic content. Our mini-map was designed as a photographically decreased view of the entire holm with all topographic elements. It was supposed to combine the perception of objects seen horizontally on the mini-map with their VR equivalents. Moreover, we employed graphic enhancement with intense coloring of the coin locations and of the gamer, so that they became the gamer's main focus $[1,45,46]$. It was debatable to place the north arrow traditionally on the map, as it could cause visual chaos. Even experts consider the north arrow an unnecessary element of multimedia cartography [43]. The size of our mini-map was adapted, according to the suggestions of designers and computer game developers, to occupy approximately $10 \%$ of the display screen available [9].

It became necessary to prepare the same task for two gamer groups in a single game to conduct a comparative analysis and draw synthetic conclusions on walking and teleportation. The total game time and the mini-map examination time were the two most relevant datasets of the research (Tables 1-3; Figures 6-8). The total game time was adopted as a factor determining the gamer's effectiveness. We assumed that an effectiveness increase occurs when the gamer finishes the game faster than the median of 20 gamers' times, and an effectiveness decrease occurs when it takes more time for the gamer to collect coins. In this analysis, our groups consisted of 20 people and both were homogeneous, in keeping with the assumptions of other multimedia cartography studies, but we recognize that more people would have to be considered for more detailed statistical research.

Optimally effective gamer's behavior would occur if the gamer examined the minimap once to identify his location and the coin, and then continued the walking or teleportation without using the mini-map anymore. This assumption turned out to be correct, as the research revealed that the more time gamers took to examine the mini-map, the more time they needed to finish the game, thus decreasing their effectiveness. On the other hand, without the mini-map, the effectiveness level would drop significantly, as gamers would have to rely solely on their intuition to find coins.

The research proved that teleporting gamers had significantly higher time effectiveness than walking gamers, however, the data obtained showed only a minor difference between the proportions of the mini-map examination time to the total game time for walking and teleportation. A higher percentage obtained for teleportation rather than walking means that a minimally longer time is needed to check one's own location and the location of coins when one moves faster. Comparing the ratio of the mini-map examination time to the total game time prior to collecting the first coin and prior to collecting the last coin came as the biggest surprise. We assumed that prior to the last coin, gamers would take less time to examine the mini-map since they already had had time to accustom themselves to the topographic space and the mini-map function when they had been collecting previous coins. It turned out gamers took much more time to examine the mini-map prior to collecting the 
last coin rather than the first one, even though the routes to the first and the last coin were highly similar. That means that the learning effect failed to appear for both gamer groups and the effectiveness level in the use of the mini-map at the beginning and at the end of the game was not related to learning the game's topography by gamers. Interestingly, the proportions are larger for teleportation, i.e., gamers would take significantly more time to examine the mini-map prior to collecting the last coin than prior to collecting the first one.

The data obtained according to the research concept adopted became the foundation for drawing the above conclusions, however, the authors of the research realize that their suggestion to use eye tracking to determine the gamer's effectiveness in moving in virtual topographic space should continue to be followed to search for guidelines on how to design parameters of the mini-map.

In our future studies, we are planning to compare different types of mini-maps, dynamic and static ones, to extend this analysis. We are also planning to compute a model that would predict user cognitive performance in virtual reality. Thus, our future research should focus on statistical analysis of different cognitive strategies of processing spatial information.

Author Contributions: Conceptualization, Krzysztof Zagata and Beata Medyńska-Gulij; Data curation, Krzysztof Zagata; Formal analysis, Krzysztof Zagata and Beata Medyńska-Gulij; Investigation, Krzysztof Zagata, Jacek Gulij and Beata Medyńska-Gulij; Methodology, Krzysztof Zagata, Jacek Gulij and Beata Medyńska-Gulij; Resources, Krzysztof Zagata, Jacek Gulij, Beata Medyńska-Gulij and Łukasz Halik; Software, Krzysztof Zagata and Jacek Gulij; Supervision, Beata Medyńska-Gulij; Validation, Krzysztof Zagata and Beata Medyńska-Gulij; Visualization, Krzysztof Zagata; Writingoriginal draft, Krzysztof Zagata, Jacek Gulij and Beata Medyńska-Gulij; Writing—review and editing, Krzysztof Zagata and Beata Medyńska-Gulij. All authors have read and agreed to the published version of the manuscript.

Funding: This paper is the result of research on visualization methods carried out within statutory research in the Department of Cartography and Geomatics, Faculty of Geographical and Geological Sciences, Adam Mickiewicz University in Poznań, Poland.

Conflicts of Interest: The authors declare no conflict of interest.

\section{References}

1. Dent, B.D. Cartography: Thematic Map Design, 5th ed.; WCB/McGraw-Hill: Boston, MA, USA, 1999.

2. Kraak, M.-J.; Ormeling, F. Cartography: Visualization of Geospatial Data, 4th ed.; CRC Press: Boca Raton, FL, USA, 2020.

3. Robinson, A.H.; Morrison, J.L.; Muehrcke, P.C.; Kimerling, A.J.; Guptill, S.C. Elements of Cartography, 6th ed.; Wiley: New York, NY, USA, 1995.

4. Forrest, D.; Pearson, A.; Collier, P. The Representation of Topographic Information on Maps-The Coastal Environment. Carto. J. 1997, 34, 77-85. [CrossRef]

5. Wielebski, Ł.; Medyńska-Gulij, B.; Halik, Ł.; Dickmann, F. Time, Spatial, and Descriptive Features of Pedestrian Tracks on Set of Visualizations. ISPRS Int. J. Geo-Inf. 2020, 9, 348. [CrossRef]

6. Medyńska-Gulij, B. Kartografia i Geomedia; Wydawnictwo Naukowe PWN: Warsaw, Poland, 2021.

7. Edler, D.; Keil, J.; Tuller, M.-C.; Bestgen, A.-K.; Dickmann, F. Searching for the 'Right' Legend: The Impact of Legend Position on Legend Decoding in a Cartographic Memory Task. Cartogr. J. 2018, 57, 6-17. [CrossRef]

8. Horbiński, T.; Cybulski, P.; Medyńska-Gulij, B. Graphic Design and Button Placement for Mobile Map Applications. Cartogr. J. 2020, 57, 196-208. [CrossRef]

9. Edler, D.; Keil, J.; Wiedenlübbert, T.; Sossna, M.; Kühne, O.; Dickmann, F. Immersive VR Experience of Redeveloped Postindustrial Sites: The Example of "Zeche Holland" in Bochum-Wattenscheid. KN J. Cartogr. Geogr. Inf. 2019, 69, 267-284. [CrossRef]

10. Hruby, F.; Castellanos, I.; Ressl, R. Cartographic Scale in Immersive Virtual Environments. KN J. Cartogr. Geogr. Inf. 2020, 21 , 1-7. [CrossRef]

11. Wessels, S.; Ruther, H.; Bhurtha, R.; Schroeder, R. Design and creation of a 3D virtual tour of the world heritage site of Petra, Jordan. In Proceedings of the AfricaGEO, Cape Town, South Africa, 1-3 July 2014.

12. Callieri, M.; Dellepiane, M.; Scopigno, R. Remote visualization and navigation of 3d models of archeological sites. ISPRS Int Arch. Photogramm. Remote Sens. Spat. Inf. Sci. 2015, 5, 147-154. [CrossRef]

13. Yuqiang, B.; Niblock, C.; Bonenberg, L. Lincoln Cathedral Interactive Virtual Reality Exhibition. In Proceedings of the 17th International Conference on Computer Aided Architectural Design Futures, Istanbul, Turkey, 12-14 July 2017. 
14. Khan, N.; Rahman, A.U. Rethinking the Mini-Map: A Navigational Aid to Support Spatial Learning in Urban Game Environments. Int. J. Hum.-Comput. Interact. 2018, 34, 1135-1147. [CrossRef]

15. Medyńska-Gulij, B.; Zagata, K. Experts and Gamers on Immersion into Reconstructed Strongholds. ISPRS Int. J. Geo-Inf. 2020, 9 , 655. [CrossRef]

16. Si, C.; Pisan, Y.; Tan, C.T.; Shen, S. An initial understanding of how game users explore virtual environments. Entertain. Comput. 2017, 19, 13-27. [CrossRef]

17. Johanson, C.; Gutwin, C.; Mandryk, R.L. The Effects of Navigation Assistance on Spatial Learning and Performance in a 3D Game. In Proceedings of the Annual Symposium on Computer-Human Interaction in Play, Amsterdam, The Netherlands, 15-18 October 2017; Association for Computing Machinery (ACM): New York, NY, USA, 2017; pp. 341-353.

18. Kłosiński, M. Hermeneutyka Gier Wideo. Interpretacja, Immersja, Utopia; Wydawnictwo IBL PAN: Warsaw, Poland, 2018.

19. Dominic, J.; Robb, A. Exploring Effects of Screen-Fixed and World-Fixed Annotation on Navigation in Virtual Reality. In Proceedings of the 2020 IEEE Conference on Virtual Reality and 3D User Interfaces (VR), Atlanta, GA, USA, 22-26 March 2020; pp. 607-615.

20. Adams, E. Fundamentals of Game Design, 3rd ed.; New Riders: Thousand Oaks, CA, USA, 2014.

21. Edler, D.; Keil, J.; Dickmann, F. Varianten interaktiver Karten in Video-und Computerspielen-Eine Übersicht. KN J. Cartogr. Geogr. Inf. 2018, 68, 57-65. [CrossRef]

22. Slater, M.; Usoh, M.; Steed, A. Taking steps. ACM Trans. Comput. Interact. 1995, 2, 201-219. [CrossRef]

23. Funk, M.; Müller, F.; Fendrich, M.; Shene, M.; Kolvenbach, M.; Dobbertin, N.; Günther, S.; Mühlhäuser, M. Assessing the Accuracy of Point \& Teleport Locomotion with Orientation Indication for Virtual Reality using Curved Trajectories. In Proceedings of the 2019 CHI Conference on Human Factors in Computing Systems, Glasgow, Scotland, UK, 4-9 May 2019; Association for Computing Machinery (ACM): New York, NY, USA, 2019; p. 147.

24. Llorach, G.; Evans, A.; Blat, J. Simulator sickness and presence using HMDs. In Proceedings of the 20th ACM Symposium on Access Control Models and Technologies, Edinburgh, Scotland, UK, November 2014; Association for Computing Machinery (ACM): New York, NY, USA, 2014; pp. 137-140.

25. Langbehn, E.; Lubos, P.; Steinicke, F. Evaluation of Locomotion Techniques for Room-Scale VR. In Proceedings of the Virtual Reality International Conference-Laval Virtual, Laval, France, 4-6 April 2018; Association for Computing Machinery (ACM): New York, NY, USA, 2018; p. 4.

26. Langbehn, E.; Steinicke, F. Redirected Walking in Virtual Reality. In Encyclopedia of Computer Graphics and Games; Springer International Publishing: Berlin, Germany, 2018; pp. 1-11.

27. Lütjens, M.; Kersten, T.P.; Dorschel, B.; Tschirschwitz, F. Virtual Reality in Cartography: Immersive 3D Visualization of the Arctic Clyde Inlet (Canada) Using Digital Elevation Models and Bathymetric Data. Multimodal Technol. Interact. 2019, 3, 9. [CrossRef]

28. Walmsley, A.P.; Kersten, T.P. The Imperial Cathedral in Königslutter (Germany) as an Immersive Experience in Virtual Reality with Integrated $360^{\circ}$ Panoramic Photography. Appl. Sci. 2020, 10, 1517. [CrossRef]

29. Medynska-Gulij, B. The Effect of Cartographic Content on Tourist Map Users. Cartography 2003, 32, 49-54. [CrossRef]

30. Wielebski, Ł.; Medyńska-Gulij, B. Graphically supported evaluation of mapping techniques used in presenting spatial accessibility. Cartogr. Geogr. Inf. Sci. 2019, 46, 311-333. [CrossRef]

31. Çöltekin, A.; Heil, B.; Garlandini, S.; Fabrikant, S.I. Evaluating the Effectiveness of Interactive Map Interface Designs: A Case Study Integrating Usability Metrics with Eye-Movement Analysis. Cartogr. Geogr. Inf. Sci. 2009, 36, 5-17. [CrossRef]

32. Smith, S.P.; Du'Mont, S. Measuring the effect of gaming experience on virtual environment navigation tasks. In Proceedings of the 2009 IEEE Symposium on 3D User Interfaces, Lafayette, LA, USA, 14-15 March 2009; pp. 3-10.

33. Cybulski, P.; Wielebski, Ł. Effectiveness of Dynamic Point Symbols in Quantitative Mapping. Cartogr. J. 2018, 56, 146-160. [CrossRef]

34. Gkonos, C.; Enescu, I.I.; Hurni, L. Spinning the wheel of design: Evaluating geoportal Graphical User Interface adaptations in terms of human-centred design. Int. J. Cartogr. 2018, 5, 23-43. [CrossRef]

35. Cybulski, P. Spatial distance and cartographic background complexity in graduated point symbol map-reading task. Cartogr. Geogr. Inf. Sci. 2020, 47, 244-260. [CrossRef]

36. Cybulski, P.; Horbiński, T. User Experience in Using Graphical User Interfaces of Web Maps. ISPRS Int. J. Geo-Inf. 2020, 9, 412. [CrossRef]

37. Mccoleman, C.; Thompson, J.; Anvari, N.; Azmand, S.J.; Barnes, J.; Barrett, R.C.A.; Byliris, R.; Chen, Y.; Dolguikh, K.; Fischler, K.; et al. Digit eyes: Learning-related changes in information access in a computer game parallel those of oculomotor attention in laboratory studies. Atten. Percept. Psychophys. 2020, 82, 2434-2447. [CrossRef]

38. Medynska-Gulij, B.; Halik, Ł.; Wielebski, Ł.; Dickmann, F. Mehrperspektivische Visualisierung von Informationen zum räumlichen Freizeitverhalten-Ein Smartphone-gestützter Ansatz zur Kartographie von Tourismusrouten. KN J. Cartogr. Geogr. Inf. 2015, 65, 323-329. [CrossRef]

39. Halik, Ł.; Medyńska-Gulij, B. The Differentiation of Point Symbols using Selected Visual Variables in the Mobile Augmented Reality System. Cartogr. J. 2017, 54, 147-156. [CrossRef]

40. Van Elzakker, C.P.; Ooms, K. Understanding map uses and users. In The Routledge Handbook of Mapping and Cartography; Informa UK Limited: London, UK, 2018; pp. 55-67. 
41. Alghofaili, R.; Sawahata, Y.; Huang, H.; Wang, H.-C.; Shiratori, T.; Yu, L.-F. Lost in Style. In Proceedings of the 2019 CHI Conference on Human Factors in Computing Systems, Glasgow, Scotland, UK, 4-9 May 2019; Association for Computing Machinery (ACM): New York, NY, USA, 2019; p. 348.

42. Burch, M. Teaching Eye Tracking Visual Analytics in Computer and Data Science Bachelor Courses. In Proceedings of the Symposium on Eye Tracking Research and Applications, Stuttgart, Germany, 2-5 June 2020; Association for Computing Machinery (ACM): New York, NY, USA, 2020.

43. Medyńska-Gulij, B.; Wielebski, Ł.; Halik, Ł.; Smaczyński, M. Complexity Level of People Gathering Presentation on an Animated Map-Objective Effectiveness Versus Expert Opinion. ISPRS Int. J. Geo-Inf. 2020, 9, 117. [CrossRef]

44. Kay, M.; Rector, K.; Consolvo, S.; Greenstein, B.; Wobbrock, J.O.; Watson, N.F.; Kientz, J.A. PVT-Touch: Adapting a Reaction Time Test for Touchscreen Devices. In Proceedings of the 2013 7th International Conference on Pervasive Computing Technologies for Healthcare and Workshops, Venice, Italy, 5-8 May 2013.

45. Cybulski, P.; Wielebski, Ł.; Medyńska-Gulij, B.; Lorek, D.; Horbiński, T. Spatial visualization of quantitative landscape changes in an industrial region between 1827 and 1883. Case study Katowice, southern Poland. J. Maps 2020, 16, 77-85. [CrossRef]

46. Smaczyński, M.; Medyńska-Gulij, B.; Halik, Ł. The Land Use Mapping Techniques (Including the Areas Used by Pedestrians) Based on Low-Level Aerial Imagery. ISPRS Int. J. Geo-Inf. 2020, 9, 754. [CrossRef] 